\title{
O PARADIGMA JUNGUIANO NO CONTEXTO DA Metodologia Qualitativa de Pesquisa ${ }^{1}$
}

\author{
Eloisa M. D. Penna ${ }^{2}$ \\ Pontifícia Universidade Católica de São Paulo \\ Sociedade Brasileira de Psicologia Analítica \\ Associação Brasileira de Psicoterapia
}

$O$ artigo discute o paradigma junguiano e suas interfaces com a metodologia qualitativa de pesquisa e a ciência pós-moderna. Primeiramente, são delineados os pressupostos básicos da ciência moderna e sua evolução para a concepção atual de ciência pós-moderna. São apresentadas as raízes filosóficas e epistemológicas do pensamento de C. G. Jung e as principais características do método qualitativo, com a finalidade de contextualizar o método junguiano de investigação da psique no panorama da pesquisa qualitativa. A Psicologia Analítica de C. G.Jung é apresentada a partir do conceito atual de paradigma, que compreende três elementos fundamentais - ontologia, epistemologia $e$ metodologia -, articulados de forma consistente e coerente. Assim, o método é necessariamente resultante da ontologia e da epistemologia. Dessa forma, a partir das noções de totalidade, consciente e inconsciente coletivo e pessoal, o conhecimento decorre da possibilidade de acesso ao inconsciente pela via do símbolo. O método de investigação psicológica se dá pela apreensão dos símbolos e sua compreensão, que resulta do processamento simbólico realizado pelo pesquisador.

Descritores: Psicologia junguiana. Pesquisa qualitativa. Ciência. Símbolo.

1 Este artigo foi baseado em trabalho apresentado no III Congresso Latino-americano de Psicologia Junguiana, em Salvador, em 2004.

2 R. Princesa Isabel, 1516 - CEP 04601-003 - São Paulo, SP. Fone/Fax 55354971. Endereço eletrônico: elopenna@uol.com.br 
onsiderando o crescente interesse por parte da comunidade acadêmica
em conduzir pesquisas baseadas na Psicologia Analítica, nosso objetivo é discutir as bases epistemológicas e metodológicas do paradigma junguiano e suas interfaces com o modelo científico pós-moderno e com os métodos qualitativos de pesquisa.

A aplicação da Psicologia Analítica à pesquisa científica abre possibilidades de atuação profissional, que vão além da prática clínica, e constitui um desafio da prática junguiana a ser enfrentado. A perspectiva simbólica arquetípica como forma de compreensão da realidade nos habilita a investigar os fenômenos nos contextos individual e coletivo.

O modelo junguiano desenvolveu-se, predominantemente, na direção da formação de analistas, privilegiando a aplicação da teoria à psicoterapia. Quando se fala de método junguiano, geralmente, entende-se método psicoterapêutico. Jung, no entanto, além de exímio psicoterapeuta, foi, antes, um grande pensador, que construiu uma teoria psicológica inédita, tanto em termos ontológicos quanto epistemológicos e metodológicos, o que nos permite falar de um novo paradigma científico.

A compreensão das interfaces do paradigma junguiano com a metodologia qualitativa de pesquisa e com a ciência pós-moderna requer algumas considerações preliminares, ainda que breves, sobre a concepção de ciência moderna, sobre as origens da Psicologia Analítica de C. G. Jung e sobre o conceito de paradigma. Tais considerações visam a contextualizar o pensamento junguiano e a metodologia qualitativa de pesquisa, para que seja possível discutir a integração entre ambos.

\section{As concepções de ciência moderna e pós-moderna}

A concepção de ciência, vigente até meados do século XX, é herdeira do racionalismo cartesiano, do iluminismo e do positivismo lógico de $\mathrm{Au}$ gusto Comte, sendo denominada ciência moderna. Esta é caracterizada e orientada, predominantemente, pelas funções de pensamento e sensação da 
consciência conhecedora e por um ponto de vista extrovertido em sua abordagem dos fenômenos.

A racionalidade destaca o pensamento lógico como uma das características fundamentais da produção científica. O empirismo destaca a observação como a ferramenta metodológica básica para a aquisição de conhecimento. A concepção materialista dos fenômenos, em que a realidade é considerada em seu aspecto material e externo ao sujeito, confere uma atitude predominantemente extrovertida ao cientista. O empirismo lógico positivista é o fundamento básico do método científico adotado nessa concepção de ciência e a ênfase na quantificação dos dados coletados está afinada com a visão racional e materialista da ciência.

A ciência moderna, a partir do século XIX, adquire estatuto de promotora exclusiva de conhecimento sério, confiável e verdadeiro na cultura ocidental e é "vista como a mais alta e mais característica façanha da cultura humana” (Cassirer, 1944/1997, p. 337).

Nesse contexto, o conhecimento científico deve ser produzido por meio de métodos de investigação com alto nível de confiabilidade, que garantam objetividade, previsibilidade, fidedignidade e generalidade.

No entanto, a partir da segunda metade do século XX, toma corpo um movimento importante na filosofia da ciência, que dará origem aos métodos qualitativos de pesquisa, estabelecendo as raízes da ciência pós-moderna. As bases do pensamento científico moderno são questionadas e criticadas por Carl Popper e Thomas Kuhn, que são alguns dos principais articuladores de uma nova metodologia científica.

Segundo Tarnas (2001), ao longo do século XX, observa-se uma crise epistemológica e metodológica na ciência ocidental, que questiona o pensamento científico moderno e Prigogine (1996) avalia que, nesse período, estamos no ponto de partida de uma nova racionalidade, em que a ciência não mais se identifica com a busca de certezas absolutas.

Os primeiros germes dessa mudança, entretanto, datam do século XVIII, com a filosofia kantiana, cujos fundamentos rompem com a tradição cartesiana. No pensamento de Kant encontram-se as primeiras tentativas de 
relativização dos métodos científicos de caráter racional, empírico e lógico e, no panorama ocidental, vários movimentos filosóficos se sucedem nessa direção, desde Kant até os dias atuais. No entanto, a ciência ocidental permaneceu aderida à tradição cartesiana em suas vertentes iluminista, positivista e tecnicista, enquanto a filosofia e a arte aderiram às vertentes neokantianas e românticas.

A filosofia romântica está na raiz da psiquiatria dinâmica que deu origem à psicologia profunda e à Psicologia Analítica de C. G. Jung.

O movimento que questiona as bases do pensamento científico moderno e resulta na concepção de ciência pós-moderna é caracterizado pela “desdogmatização da ciência” (Santos, 2000) e suas principais características da pós-modernidade, de acordo com Hauke (2001), são: pluralidade de pontos de vista, diversidade de epistemologias e métodos, aceitação de paradoxos e contradições, inevitabilidade de imprecisão e incerteza, ênfase na relatividade dos parâmetros e na polivalência de significados, concepção de verdade transitória e relativa, valorização do auto-conhecimento e, por conseguinte, da subjetividade na aquisição e na produção de conhecimento e integração da individualidade na coletividade. Como veremos mais adiante, muitas dessas características já estavam presentes nas formulações da psiquiatria dinâmica e na Psicologia Analítica.

O questionamento dos pressupostos básicos da ciência moderna conduz a um processo de reformulação no método científico, dando origem a uma vertente na ciência que privilegia a metodologia qualitativa de pesquisa. Na segunda metade do século XX, vemos as metodologias quantitativas e qualitativas sendo utilizadas paralelamente, mas, em algumas áreas, ainda prevalecem os métodos quantitativos baseados na epistemologia da ciência moderna.

\section{A Psicologia Analítica}

A Psicologia Analítica de C. G. Jung é fortemente influenciada pela filosofia de Kant e dos filósofos românticos alemães, pela metodologia da 
psiquiatria dinâmica e pela necessidade da prática clínica cotidiana de Jung. "O problema que ocupava o primeiro plano de meu interesse e de minhas pesquisas era o seguinte: o que se passa no espírito do doente mental.” (Jung, 1961/1981 p. 108).

A psiquiatria dinâmica é um movimento dentro da medicina européia que desponta em meados do século XVIII (Ellenberger, 1970), calcado na preocupação com a compreensão e o tratamento das doenças mentais, reunindo conhecimentos médicos e filosóficos. As bases epistemológicas e metodológicas da psiquiatria dinâmica são afinadas com o método dialético neo-kantiano e com as concepções da filosofia romântica. Ou seja, a psiquiatria dinâmica é um movimento que revoluciona a mentalidade médica quanto à abordagem da doença mental e antecipa, em vários aspectos, a concepção de ciência e pesquisa atuais.

Charcot, com seus estudos e pesquisas, conclui que "existiam fatores desconhecidos e poderosos de cura que a medicina do futuro deveria aprender a controlar" (Ellenberger, 1970, p. 764). Com isso, a hipótese da gênese psíquica da doença mental começa a ser considerada e a noção de inconsciente é reabilitada. Com Pierre Janet, surge a proposta de uma compreensão psicológica dos sintomas mentais e a preocupação com transformações mais duradouras, uma vez que os métodos sugestivos apresentavam resultados muito efêmeros. A psiquiatria dinâmica propõe uma psicopatologia mais compreensiva do que descritiva e ressalta a importância de considerar o ser humano em sua subjetividade, mais do que em sua generalidade.

A partir das proposições da psiquiatria dinâmica, no início do século XX, surge uma vertente psicodinâmica na medicina, integrando psiquiatras, neurologistas e filósofos, que dá origem aos métodos psicoterapêuticos atuais. Nesse panorama científico-cultural, a psicanálise de Freud representa a primeira elaboração e sistematização de estudos e pesquisas conduzidos a partir dos pressupostos da psiquiatria dinâmica. A Psicologia Analítica de C. G. Jung é também herdeira dessa tradição, embora mais vinculada à filosofia romântica do que à psicanálise de Freud. 
Segundo Clarke (1993), Jung antecipa as proposições de Carl Popper e Thomas Kuhn, principais articuladores da metodologia qualitativa de pesquisa, e compartilha as idéias da física quântica, principalmente as proposições de Heisenberg e Bohr, quanto à relatividade e incerteza do conhecimento. Concordando com Nietzsche, Jung critica a exigência de objetividade que exclui a subjetividade nos métodos científicos, declarando que conhecimento e autoconhecimento são indissociáveis e condicionados pela psique do pesquisador.

Ellenberger (1970) considera Jung um dos pioneiros na investigação do inconsciente e precursor do método interpretativo na psiquiatria dinâmica do século XX, com o teste de associação de palavras e a interpretação simbólica do material psíquico. Méier (apud Clarke, 1993) comenta o trabalho realizado por Jung, no hospital Bürgholzli, “pela primeira vez na história da psiquiatria, material ilusório é tratado como mais do que coisas ininteligíveis e examinado como algo digno de interpretação” (Clarke, 1993, p. 27).

Wehr (1988) caracteriza o trabalho de Jung “como uma linha de pesquisa psicológica que ocupou seu espaço no cânone cultural, foi além de si mesma e forma uma ponte para outras disciplinas” (p. 489), e o identifica como um dos primeiros a praticar a interdisciplinaridade na busca de conhecimento.

Von Franz (1975/1992) o considera pioneiro na investigação dos fenômenos psicológicos pela concepção de um inconsciente espontâneo e criativo e por sua forma de pesquisar o material inconsciente. Segundo a autora, "a compreensão junguiana do inconsciente marca o fim do racionalismo científico do século XIX” (p. 14).

As idéias de Jung, entretanto, foram duramente criticadas e combatidas pela comunidade científica até meados do século XX. Quanto a essa incompreensão e desaprovação, Von Franz (1975/1992) avalia que:

O crescimento de sua influência encontra-se ainda em seus estágios iniciais; daqui a trinta anos poderemos, com toda probabilidade, discutir sua obra em termos bem diferentes dos atuais (...) Jung estava a tal ponto à frente de sua época que as pessoas somente aos poucos começam a alcançar suas descobertas. (Von Franz, 1975/1992, p. 11) 
Byington (informação verbal) ${ }^{3}$ considera a psicanálise de Freud uma mensagem condizente com a mentalidade ocidental do século XX e, a psicologia de Jung, uma proposta a ser compreendida no século XXI; Tarnas (2001) situa Jung dentre os formadores da mentalidade pós-moderna.

A Psicologia Analítica transcendeu o âmbito da psicoterapia e tem sido aplicada em outras áreas do conhecimento, tais como pedagogia, sociologia e história comparada das religiões, entre outras.

Conforme Von Franz (1975/1992), o trabalho de Eric Neumann demonstra que a "teoria dos arquétipos vem se tornando de forma gradual e crescente, a base de uma nova antropologia geral” (Von Franz, 1975/1992, p. 109). Segundo Neumann (1949/1989), a investigação dos estágios arquetípicos de desenvolvimento, aplicada à história da humanidade, "proporciona uma melhor orientação psicológica em várias disciplinas, por exemplo, a história das religiões, a antropologia, o folclore, e outras” (Neumann, 1949/1989, p. xvii).

De acordo com Nagy (1991), a Psicologia Analítica pode ser considerada, hoje, um sistema filosófico que vai além da psicoterapia. Wehr (1988) sugere que a psicologia de C. G. Jung transcende as fronteiras da psicoterapia e se constitui um corpo teórico aplicável à pesquisa em vários campos fora da psicoterapia. Progoff (1985) considera Jung um dos pioneiros da abordagem "holista” do ser humano e defende a aplicação da Psicologia Analítica à sociologia.

A teoria dos arquétipos foi além da acumulação e classificação de dados empiricamente coletados ou experiências fenomenológicas, apresentando uma hipótese ousada e, inicialmente, de caráter especulativo, mas destinada a explicar uma ampla faixa de fenômenos que se encontravam excluídos da investigação científica.

Cumpre salientar, no entanto, que o valor e reconhecimento da psicologia junguiana permanecem, ainda, estreitamente associados ao método

3 Seminário dado pelo autor no Curso de Formação de analistas junguianos, na SBPA, em 1989. 
psicoterapêutico como área de maior concentração, até hoje, de estudos e pesquisas. No entanto, para que sua aplicabilidade realmente se estenda para além do âmbito clínico é necessária a formulação de uma metodologia de pesquisa própria desse paradigma.

O método de investigação da psique proposto por C. G. Jung compreende características do pensamento dialético, fenomenológico, hermenêutico, associativo, analógico e imagético. As premissas da Psicologia Analítica são condizentes com a noção atual de paradigma e com a metodologia qualitativa de pesquisa em muitos aspectos (Penna, 2003), demonstrando maior sintonia com a concepção de ciência atual do que com a concepção de ciência do início do século passado. Isso justifica, em grande parte, as resistências e incompreensões em relação ao pensamento de Jung, sobretudo na primeira metade do século XX, quando ainda prevaleciam os padrões positivistas de cientificidade.

\section{$O$ conceito de paradigma e a metodologia qualitativa}

O termo "paradigma”, originalmente, significa modelo ou exemplo (Abbagano, 1999), tendo sido utilizado por Platão, no primeiro sentido, e por Aristóteles, no segundo. Em Platão, o termo paradigma tem o sentido de modelo, sendo associado a arquétipo como "modelos perfeitos, eternos, imutáveis dos objetos existentes no mundo natural que são cópias desses modelos”. Em Aristóteles, paradigma equivale a exemplo (Japiassu \& Marcondes, 2001).

A noção de paradigma foi reabilitada e inserida no panorama da filosofia das ciências, em 1962, por Thomas Kuhn em seu livro “A estrutura das revoluções científicas”, no qual critica a ciência positivista e é duramente criticado pela comunidade científica da época. Suas principais críticas referem-se ao método empírico quantitativo, destacando a estreiteza de seus limites e a exigência de uma objetividade impossível de ser mantida ou mesmo alcançada. Thomas Kuhn é criticado por defender uma visão relativista de ciência, negar a existência de critérios objetivos para a avaliação de 
teorias e, principalmente, por defender a forte influência que fatores psicológicos e sociais exercem em qualquer tipo de investigação e avaliação que se queira fazer.

Podemos observar que as críticas proferidas por Kuhn se assemelham muito às críticas feitas por Jung, já em 1896, quando este declara, pela primeira vez, que o pressuposto materialista e racionalista da ciência contém premissas por demais estreitas para o conhecimento da vida humana (Jung, 1983), principalmente diante da hipótese do inconsciente. Em 1912, Jung já considerava o método experimental insuficiente e inadequado para a pesquisa do inconsciente (Jung, 1912/1980).

Segundo Mazzotti e Gewadsznajder (1998), “para Kuhn, a pesquisa científica é orientada não apenas por teorias, no sentido tradicional deste termo (conjunto de leis e conceitos), mas por algo mais amplo - o paradigma - que constituiria uma 'teoria ampliada'” (p. 24).

Tarnas (2001) aponta o conceito kuhniano de paradigma como uma das características principais do pensamento pós-moderno, "refletindo uma consciência crítica da natureza essencialmente interpretativa da cultura” (Tarnas, 2001, p. 424) contemporânea, que não se satisfaz mais com a simples constatação dos fatos, mas deseja compreendê-los e interpretá-los criticamente.

Os métodos qualitativos de pesquisa propõem uma abordagem compreensiva e interpretativa dos fenômenos. A maioria dos autores considera que toda pesquisa é interpretativa, guiada por um conjunto de crenças e sentimentos sobre o mundo, que norteia o modo como os fenômenos devem ser investigados (Denzin \& Lincoln, 1998; Guba, 1990; Lincoln \& Guga, 1985).

A articulação dessas transformações, nos paradigmas científicos atuais, surge principalmente nas ciências humanas, pois, segundo Denzin e Lincoln (1998), “o comportamento humano diferentemente dos objetos físicos não pode ser compreendido sem referência aos significados e propósitos atribuídos pelos humanos às suas atividades” (p. 107)4.

4 Citações de textos consultados em inglês foram traduzidos pela autora. 
Entretanto, os primeiros golpes contra a ciência positivista foram desferidos pela Física com Einstein, Heisemberg, Bohr e Pauli, além de outros físicos contemporâneos.

A Física foi pioneira na proposição da relatividade dos parâmetros científicos, do princípio da incerteza, da impossibilidade de objetividade pura e da transitoriedade da verdade nas investigações científicas.

Somente a partir da década de 1970, a pesquisa qualitativa começa a ser definida e realmente praticada nas ciências humanas. Segundo Denzin e Lincoln (1998), por mais de duas décadas uma revolução metodológica foi se dando nas ciências sociais em direção a uma abordagem interpretativa e qualitativa dos fenômenos.

A palavra qualitativa implica uma ênfase em processos e significados que não são rigorosamente examinados ou medidos (se medidos), em termos de quantidade, intensidade ou freqüência. Pesquisadores qualitativos enfatizam a relação íntima entre o pesquisador e o que é estudado, e os limites situacionais da investigação. Eles buscam respostas para questões que enfatizam como a experiência é criada e significada. Em contraste, estudos quantitativos enfatizam a medida e análise de relações causais entre variáveis e não os processos. (Denzin \& Lincoln, 1998, p. 8)

A pesquisa qualitativa caracteriza-se como uma abordagem interpretativa e compreensiva dos fenômenos, buscando seus significados e finalidades. Essa metodologia baseia-se numa perspectiva epistemológica em que o conhecimento resulta de processos dinâmicos que fluem dialeticamente. Do princípio da relatividade, da complementaridade e da incerteza deriva uma concepção de verdade relativa e temporária. Do ponto de vista metodológico, os fenômenos são considerados em função do contexto em que são investigados; tanto a objetividade quanto a subjetividade são consideradas, sendo que a intersubjetividade se configura como a melhor posição possível do pesquisador diante do conhecimento e de seu objeto de investigação. A metodologia qualitativa de pesquisa é resultante de um movimento que avalia e critica o método científico moderno. Essa proposta exige do pesquisador coerência e consistência epistemológicas, envolvimento pessoal com a investigação e, sobretudo, uma atitude crítica e ética frente ao conhecimento e às comunidades social e científica a que pertence. A produção de conhe- 
O Paradigma Junguiano no Contexto da Metodologia Qualitativa de Pesquisa

cimento científico, no contexto da pesquisa qualitativa, visa não apenas à descrição dos fenômenos, mas, principalmente, à compreensão e interpretação da realidade pesquisada.

\section{O paradigma junguiano: perspectivas ontológica e metodológica}

O método de investigação da psique, proposto por C. G. Jung, será analisado a partir do conceito atual de paradigma. Dessa forma, pretendemos fazer uma sistematização do método junguiano no contexto da metodologia qualitativa de pesquisa.

O paradigma é considerado como "uma rede de premissas epistemológicas e ontológicas que - a despeito de sua veracidade ou falsidade última - se tornam autovalidadas” (Bateson, 1972, p. 314) e configuram procedimentos metodológicos compatíveis.

Segundo Denzin e Lincoln (1998), a noção de paradigma envolve três elementos fundamentais: ontologia, epistemologia e metodologia, que devem estar entrelaçados de forma consistente e coerente. A perspectiva metodológica de um paradigma define-se em estreita conexão com as perspectivas ontológica e epistemológica adotadas pelo cientista. O método é um indicador do modo pelo qual o conhecimento será construído dentro de um paradigma.

No paradigma junguiano, a perspectiva ontológica refere-se à natureza da realidade, considerando as concepções de mundo, ser e psique. A noção de totalidade - unidade e diversidade - constitui o pilar básico dessa perspectiva. Trata-se de uma totalidade dinâmica que contém elementos diversos.

O mundo, para Jung, é concebido em seus aspectos subjacente e manifesto. A noção de unus mundus, emprestada da filosofia medieval, confere dinamismo ao todo e integra microcosmo e macrocosmo.

O ser humano é considerado uma totalidade eco-bio-psico-social, incluindo consciente e inconsciente (Penna, 2003). O homem como micro- 
cosmo é parte integrante do macrocosmo, o qual compreende as esferas do inconsciente coletivo e da consciência coletiva.

A noção de realidade psíquica, formulada por Jung, confere estatuto empírico ao psiquismo (Tarnas, 2001), dando substância à experiência interior. O mundo e o ser humano são definidos por sua qualidade simbólica. Dessa forma, o ser humano é um ser simbólico, que vive numa dimensão simbólica. Segundo Cassirer (1944/1997), o homem é um animal "symbolicum”, que não vive mais num universo meramente físico. O universo humano é simbólico, estamos diante de uma nova dimensão de realidade: a dimensão simbólica. Esta abarca os aspectos biológicos, ambientais, culturais (sócio-históricos) e espirituais, integrando-os num todo único e típico. A psique constitui uma totalidade que inclui o âmbito inconsciente, relacionado aos fenômenos do mundo subjacente, e o âmbito consciente, relativo aos fenômenos do mundo manifesto.

A concepção romântica de uma realidade subjacente interferindo na realidade manifesta e a noção de uma totalidade abrangente movida por padrões organizadores, isto é, arquétipos fora do controle da consciência (Bohm, 2001), constituem a base da ontologia junguiana, que hoje começa a ser aceita por outros paradigmas.

A perspectiva epistemológica, por sua vez, refere-se às possibilidades e limites do conhecimento e a relação entre o pesquisador e o objeto a ser conhecido.

Na Psicologia Analítica, conhecimento equivale a consciência, e o conhecimento e o autoconhecimento são inseparáveis. O processo de aquisição e construção de conhecimento é um processo de ampliação da consciência, denominado, por Jung, processo de individuação. Trata-se de um processo gradual e constante de integração de aspectos do inconsciente e do mundo na consciência, visando à integração na comunidade humana e em simesmo, num movimento de crescente complexidade e diversidade.“A individuação é o tornar-se um consigo mesmo, e ao, mesmo tempo, com a humanidade toda, em que também nos incluímos” (Jung, 1929/1987, p. 103). 
O Paradigma Junguiano no Contexto da Metodologia Qualitativa de Pesquisa

\section{Possibilidades e limites do conhecimento}

A epistemologia junguiana concentra-se, principalmente, na possibilidade e nos limites de acesso ao inconsciente. A possibilidade de acessar o mundo subjacente (inconsciente) repousa na hipótese de que este se expressa na realidade manifesta (consciente).

De acordo com Cassirer (1944/1997), a única forma de se conhecer o ser humano é através de suas manifestações, que são "os fios que tecem a rede simbólica da experiência humana” (Cassirer, 1944/1997, p. 48).

Para Jung, o inconsciente não é passível de um contato direto; ele se dá a conhecer apenas por meio da consciência, que constitui o ponto de partida de todo conhecimento em Psicologia.

A psicologia como ciência relaciona-se, em primeiro lugar, com a consciência; a seguir, ela trata dos produtos do que chamamos psique inconsciente, que não pode ser diretamente explorada, por estar a um nível desconhecido, ao qual não temos acesso. O único meio de que dispomos, neste caso, é tratar os produtos conscientes de uma realidade, que supomos originários do campo inconsciente, esse campo de 'representações obscuras' ao qual Kant, em sua Antropologia, se refere como sendo um mundo pela metade. Tudo que conhecemos a respeito do inconsciente foi-nos transmitido pelo próprio consciente. A psique inconsciente, cuja natureza é completamente desconhecida, sempre se exprime através de elementos conscientes. Não se pode ir além desse ponto. (Jung, 1935/1981, p. 3)

O inconsciente, embora não seja passível de observação direta, pode ser investigado e conhecido indiretamente, por meio de suas manifestações simbólicas arquetípicas.

O fenômeno psíquico investigado pela Psicologia Analítica é o símbolo, que constitui a única chave possível para o conhecimento, pois "sempre exprimimos através de símbolos as coisas que não conhecemos” (Jung, 1928/1985, p. 114).

O símbolo é o canal através do qual o mundo subjacente e o mundo manifesto se encontram. Ele congrega o âmbito pessoal e o âmbito coletivo, a dimensão histórica e a dimensão universal dos fenômenos psíquicos, e 
coloca-se como o elemento ou o fenômeno a ser apreendido pela consciência, podendo ser compreendido, quando elaborado.

Segundo Jung (1921/1991), o símbolo pressupõe uma função psíquica que o cria e uma função que o compreende, a qual denominou de "pensamento simbólico ou entendimento simbólico” (Jung, 1921/1991, p. 111), que é coordenado pelo ego e realiza a transformação de material inconsciente em material consciente.

Segundo Jacobi (1957/1986), a capacidade da psique de formar símbolos, chamada função transcendente, é uma função complexa, operada pela psique por meio do mecanismo de auto-regulação, que une os pares de opostos numa síntese e cria uma comunicação entre consciente e inconsciente.

A distinção entre o arquétipo em si e a manifestação arquetípica é essencial para a metodologia de pesquisa da Psicologia Analítica.

Quando o arquétipo aparece no aqui e agora do espaço e do tempo, podendo ser, de algum modo, percebido pelo consciente, falamos, então, de símbolo. Dessa forma, cada símbolo é também um arquétipo, mas isso não quer dizer que um arquétipo seja idêntico a um símbolo. Quando existe uma constelação psíquica geral ou uma posição adequada do consciente, ele (arquétipo) está sempre pronto a aparecer como símbolo (Jacobi, 1957/1986, p. 72).

O símbolo, portanto, é o fenômeno psíquico que permite acesso ao inconsciente, tornando possível o conhecimento. O símbolo, como manifestação do arquétipo, situa-se no limiar da possibilidade de conhecimento, pois o arquétipo, em si, está fora dos limites do conhecimento.

Do ponto de vista individual, o conhecimento do ser humano se dá por intermédio de suas manifestações subjetivas, como sonhos, fantasias e sintomas. Do ponto de vista coletivo, o conhecimento do humano se dá por suas manifestações coletivas, isto é, culturais, tais como na mitologia, no folclore, na arte, nos eventos históricos e sociais.

Na Psicologia, a psique é tanto sujeito como objeto do conhecimento, e esse é um ponto crucial na discussão da relação que se estabelece entre a consciência conhecedora e o objeto do conhecimento. Jung considerava ser esse o grande desafio na busca de métodos em Psicologia. Nesse sentido, 
cumpre salientar as especificidades da relação entre sujeito e objeto na pesquisa junguiana e ressaltar a dinâmica entre subjetividade e objetividade do pesquisador.

A questão da objetividade nos paradigmas científicos foi amplamente discutida e debatida por Kant, depois pelos filósofos românticos e por Nietzsche, que afirma a impossibilidade de objetividade, uma vez que o conhecimento produzido por um pensador está, inevitavelmente, impregnado de sua personalidade. No século XX, a questão da objetividade e da subjetividade na ciência esteve no centro dos debates sobre critérios de cientificidade na formulação de métodos qualitativos de pesquisa.

Para Jung, o conhecimento também é, inevitavelmente, fruto da personalidade do pesquisador, que necessariamente interfere no fenômeno observado. Assim como uma partícula atômica sofre a interferência do observador, também “o arquétipo se altera ao se tornar consciente e ser percebido, e toma as cores da consciência individual na qual ele aparece” (Jung, 1934/2002, p. 17).

Não se trata, no entanto, de anular as diferenças entre sujeito e objeto, pois isso inviabilizaria a própria possibilidade de conhecimento, visto que nela está implícita a presença do conhecedor, o sujeito, e do conhecido, o objeto, melhor dizendo, do desconhecido a ser conhecido.

A relação entre sujeito e objeto - pesquisador e fenômeno - é uma relação dialética e simbólica, em que sujeito e objeto participam ativamente do conhecimento. Essa dialética deve ser balanceada de tal forma que sejam evitadas posições unilaterais. Se a subjetividade for desconsiderada, ela permanecerá inconsciente no processo de conhecimento e, como tal, tenderá a se projetar de forma automática e primitiva. Entre a objetividade e a subjetividade, o máximo que se pode almejar é uma intersubjetividade, evitandose tanto o ‘subjetivismo’ como o ‘objetivismo’.

Em nenhum outro campo como na psicologia é requisito básico que o observador deve ser adequado ao seu objeto, no sentido de ser capaz de ver, não apenas subjetivamente, mas também objetivamente. A exigência de que ele deva ver apenas objetivamente está fora de questão, pois isto é impossível. Devemos ficar satisfeitos se ele não vir subjetivamente demais. (Jung, 1921/1991, p. 26) 
Nesse sentido, a metodologia junguiana propõe um método de investigação dos fenômenos que inclui tanto uma perspectiva subjetiva quanto objetiva da realidade psíquica, e permite que sejam conduzidas pesquisas no nível pessoal e no nível coletivo. O método junguiano aplicado à psicoterapia tem como ênfase principal o aspecto subjetivo e visa a compreender a dinâmica psíquica a partir das manifestações individuais. A aplicação do método junguiano a outros contextos condicionará o grau de prioridade em que os aspectos subjetivos e objetivos serão enfatizados e quais as manifestações que serão alvo de investigação.

\section{Perspectiva metodológica: apreensão e compreensão dos fenômenos}

A perspectiva metodológica diz respeito ao modo como o conhecimento sobre o mundo é adquirido e acumulado. Os métodos qualitativos de investigação compreendem duas grandes etapas, quais sejam: coleta de material ou apreensão dos fenômenos a serem investigados e análise do material ou compreensão dos dados coletados.

A emergência de um símbolo conta com a anuência da consciência, no sentido de que, em razão do mecanismo de auto-regulação da psique, o ego “deseja e precisa” da mensagem contida no símbolo, embora isso não seja garantia de sua compreensão.

O aspecto consciente do símbolo consiste na forma reconhecível de que o símbolo se reveste e pela qual é captado pela consciência que o reconhece. Seu aspecto desconhecido representa o enigma a ser decifrado, que constitui, justamente, aquilo de que a consciência se ressente no momento. O símbolo é sempre algo intrigante e instigante para a consciência que o vivencia; seu caráter ambivalente e paradoxal produz uma sensação simultânea de plenitude e vazio.

A presença de um símbolo se manifesta pela experiência numinosa que ele provoca. Em geral, um evento simbólico é considerado significativo para o indivíduo, no caso de símbolos individuais, ou para a comunidade, no caso de símbolos coletivos. A justificativa e a relevância do fenômeno pes- 
quisado é dada pelo valor simbólico deste, tanto no nível individual quanto coletivo - cultural.

O contexto em que o fenômeno ocorre também deve ser considerado na investigação psicológica. O contexto mais amplo e geral de um fenômeno psicológico qualquer é o âmbito arquetípico e o contexto mais estrito e específico do fenômeno é o âmbito individual. Entre esses dois pólos, há gradações que devem ser observadas de acordo com a situação e objetivo da investigação em curso.

A apreensão do fenômeno se dá pela observação e auto-observação na perspectiva simbólica arquetípica. A observação se constitui por uma experiência viva de participação e diálogo entre observante e observado, em que ambos são transformados pelo processo de conhecimento.

Os instrumentos de coleta de dados utilizados pela Psicologia Analítica são aqueles que fornecem a melhor forma possível de detectar e recolher o material simbólico. Os instrumentos de pesquisa utilizados são recursos projetivos em geral. As técnicas expressivas favorecem a apreensão dos símbolos. Sonhos, fantasia dirigida, imaginação ativa, relaxamento, meditação, desenho, pintura, expressão corporal, dramatização, sandplay são utilizados para acessar material inconsciente. Pode-se, também, lançar mão de questionários e entrevistas abertas ou semi-abertas, desde que formulados de modo a captar conteúdos conscientes e inconscientes.

Segundo Jung (1921/1991), a função que entende o símbolo, utilizada na análise do material coletado, é conduzida pelo pensamento simbólico que opera por associações, comparações e analogias entre diversas áreas do conhecimento e entre as diversas funções da consciência. A compreensão dos fenômenos, ou seja, a análise do material coletado é realizada por meio do processamento simbólico, que constitui a ferramenta indispensável para a melhor compreensão dos fenômenos investigados. A integração das funções da consciência nesse processo promove uma produção de conhecimento de ordem intelectiva, perceptiva, valorativa e intuitiva. Dessa forma, mais do que um pensamento simbólico, como foi proposto por Jung, trata-se de um processamento simbólico do material. 
Tal processamento se realiza, também, a partir de alguns parâmetros que devem ser rigorosamente observados, tanto na apreensão como na compreensão dos fenômenos: a causalidade, a finalidade e a sincronicidade presentes nos eventos simbólicos. Dessa forma, a função transformadora do símbolo é efetivada, isto é, o potencial transformador do símbolo se realiza e a transformação necessária, exigida pela totalidade, é alcançada.

O conhecimento é produzido à medida que aspectos do inconsciente ou da realidade existencial, antes desconhecidos, passam a fazer parte do sistema ego-consciência, operando uma ampliação da consciência, o que, em termos científicos, significa a produção de conhecimento, e para o indivíduo, o processo de individuação.

Resumindo: o método de investigação da Psicologia Analítica se caracteriza pelo processamento simbólico do material pesquisado, utilizandose a amplificação simbólica como meio através do qual os aspectos desconhecidos do símbolo se tornam conhecidos.

\section{Conclusão}

Os diversos aspectos do método de investigação psicológica, proposto por C. G. Jung, aqui apresentados, demonstram que muitos são os pontos de aproximação entre o paradigma junguiano e as características da ciência pós-moderna e da metodologia qualitativa de pesquisa. Jung reafirma o paradoxo e a contradição do ser humano e, também, sua infinita complexidade e diversidade. Sua psicologia está alinhada com uma visão integrativa e construtiva do conhecimento.

A diversidade, as contradições e incertezas da atualidade exigem flexibilidade e recusa de ortodoxias e visões unilaterais. A noção da relatividade e transitoriedade da verdade científica na Psicologia Analítica deve ser sublinhada. Observamos, na obra de C. G. Jung, sua conviç̧ão quanto à impossibilidade de se alcançar a verdade sobre a psique. O máximo que se consegue são “expressões verdadeiras” (Jung, 1929/1990, p. 324) na observação e compreensão da experiência psíquica. 
A verdade revela-se na maior aproximação possível que a consciência humana pode atingir do desconhecido. A verdade, na ciência, pode ser considerada apenas uma "hipótese, momentaneamente, satisfatória, mas não um artigo de fé eternamente válido” (Jung, 1961/1981, p. 143). A aproximação entre consciente e inconsciente se realiza pela função transcendente, que produz os símbolos, e a elaboração destes conduz a consciência ao que há de mais verdadeiro e necessário, para ela, no contexto atual.

Apesar da relatividade, da incerteza e da desdogmatização do conhecimento e da verdade, a ciência na pós-modernidade faz exigências quanto à ética do cientista. Nesse sentido, o paradigma junguiano exige uma atitude íntegra do indivíduo perante o mundo e consigo mesmo. A integridade do ser humano é definida por sua atitude responsável e comprometida frente ao conhecimento do mundo externo e ao seu autoconhecimento. Considerandose que cada indivíduo faz parte de um todo maior, tanto em termos do inconsciente coletivo como em relação à consciência coletiva (cultura), cabe ao ego participar, colaborar e se comprometer com a totalidade. Seu livre arbítrio é tanto limitado pelo âmbito coletivo quanto o influencia. A passividade e/ou a omissão do indivíduo diante do conhecimento adquirido podem ser desastrosas, à medida que dão livre curso aos conteúdos não humanizados do inconsciente.

Não existe nenhuma razão para querer conhecer mais do inconsciente coletivo do que se consegue por meio de sonhos e intuições. Quanto mais se sabe sobre ele, maior e mais pesada a responsabilidade moral, porque os conteúdos do inconsciente se transformam em tarefas e responsabilidades individuais tão logo começam a se tornar conscientes. (Jung, 1991, p. 389)

Tanto a arrogância prepotente diante do desconhecido quanto a passividade impotente diante da oportunidade de conhecimento configuram atitude irresponsável e antiética.

Do ponto de vista ontológico, o paradigma junguiano se define pelo pressuposto da totalidade abrangente que inclui as dimensões consciente e inconsciente. Baseia-se na concepção de um inconsciente arquetípico como estrutura psíquica básica e original, da qual a consciência emerge, e de um 
inconsciente pessoal que é, apenas, relativamente desconhecido. A noção de realidade psíquica confere o estatuto de fenômeno às manifestações psíquicas (Tarnas, 2001). Da dimensão simbólica do ser e do mundo resulta uma concepção ontológica em que o único e o típico se entrelaçam e compõem a totalidade.

Do ponto de vista epistemológico, a premissa de um inconsciente inacessível à observação direta constitui o principal desafio da psicologia junguiana. A perspectiva simbólica considera que o inconsciente se torna acessível por meio de suas manifestações. O conhecimento, então, é viável por intermédio das manifestações simbólicas. Como ponte entre o mundo arquetípico, o mundo da consciência e o mundo externo, o símbolo constitui o fenômeno psíquico apreensível e compreensível. A função psíquica que cria os símbolos é a função transcendente, que opera a aproximação entre consciente e inconsciente, a partir da necessidade atual de transformação da totalidade. O conhecimento se dá por um processo natural e contínuo de integração gradual e crescente de elementos do inconsciente e do mundo existencial na consciência - o processo de individuação. Tal processo constrói a individualidade do ser humano e tem correspondência na constituição das particularidades sócio-históricas da cultura humana.

A investigação psicológica na Psicologia Analítica considera os fenômenos em seu âmbito individual (sonhos, fantasias, experiências pessoais) e coletivo (mitos, contos de fadas, acontecimentos sociais e políticos), desde que revestidos de valor simbólico, seja para o indivíduo ou a coletividade que os produz e os vivencia psicologicamente.

Do ponto de vista metodológico, o caminho pelo qual o conhecimento é alcançado e viabilizado é o processamento simbólico, que se dá a partir dos parâmetros da causalidade, da finalidade e da eventual sincronicidade, presentes nos eventos simbólicos.

A compreensão do fenômeno - símbolo - abrange as etapas de tradução, interpretação, elaboração e integração do desconhecido à consciência conhecedora. A função psicológica que compreende os símbolos opera por associações, comparações, analogias e pela busca de sentido e integração do 
desconhecido na consciência. O processamento simbólico visa a elucidar, enriquecer, ampliar e aprofundar os significados ocultos do símbolo, a fim de atingir sua integração na consciência.

Concluindo, o método de investigação da psique na obra de C. G. Jung é definido pela perspectiva simbólica arquetípica que norteia o tratamento metodológico dispensado ao material psicológico, ou seja, o processamento simbólico.

Penna, E. M. D. (2005). The Jungian paradigm within the context of a qualitative research methodology. Psicologia USP, 16(3), 71-94.

\begin{abstract}
The article discusses the Jungian paradigm and its interface with a qualitative research methodology and post modern science. First the basic assumptions of modern science are explained and the evolution towards the current concept of post modern science. The philosophical and epistemological roots of C.G.Jung's thought and the main characteristics of a qualitative method are described in order to contextualize the Jungian method for investigating the psyche within a qualitative research panorama. The analytical psychology of C.G.Jung is presented based on the current concept of paradigm - which involves three fundamental elements ontology, epistemology and methodology - articulated and interconnected in a consistent and coherent manner. Thus method results from ontological and epistemological perspectives. Through the notion of totality, collective and personal conscious and unconscious, knowledge is acquired by the possibility to access the unconscious through the symbols and the method of psychic investigation concerns the symbol apprehension and its comprehension is conducted by the researcher's symbolic processing of data.
\end{abstract}

Index terms: Jungian psychology. Qualitative research. Science. Symbol. 
Penna, E. M. D. (2005). Le paradigme jungien dans le cadre de la méthodologie qualitative de recherche. Psicologia USP, 16(3), 71-94.

Résumé : L'article discute le paradigme jungien et ses interfaces avec la méthodologie qualitative de recherche et la science postmoderne.D'abord sont tracés les présupposés de base de la science moderne et son évolution pour la conception courante de la science postmoderne. Les racines philosophiques et épistemologiques de la pensée de C. G. Jung sont presentées, aussi que les caractéristiques principales de la méthode qualitative ayant pour but de contextualiser la méthode jungienne d'enquête de la psyché dans le cadre de recherche qualitative. La psychologie analytique de C. G. Jung est présentée à partir du concept courant de paradigme qui comprend trois éléments de base - ontologie, épistémologie et méthodologie - articulés d'une façon consistante et logique. De ce fait, la méthode est nécessairement résultant de l'ontologie et de l' épistémologie. De cette forme, à partir des notions de totalité, conscience et inconscient, collectif et personnel, la connaissance est résultante de la possibilité d'accès à l'inconscient par moyen du symbole. La méthode d'enquête psychologique est donnée pour l'appréhension des symboles et de leur compréhension, qui résulte du traitement symbolique exécuté par le rechercheur.

Mots-clés: Psychologie jungienne. Recherche qualitative. Science. Symbole.

\section{Referências}

Abbagnano, N. (1999). Dicionário de filosofia. São Paulo: Martins Fontes.

Bateson, G. (1972). Steps to an ecology of mind. NewYork: Ballantine.

Bohm, D. (2001). A totalidade e a ordem implicada - uma nova percepção da realidade. São Paulo: Cultrix.

Cassirer, E. (1997). Um ensaio sobre o homem: introdução a uma filosofia da cultura humana. São Paulo: Martins Fontes. (Trabalho original publicado em 1944)

Clarke, J. (1993). Em busca de Jung: indagações históricas e filosóficas. Rio de Janeiro: Ediouro.

Denzin, N. K., \& Lincoln, S. Y. (1998). The landscape of qualitative research: theories and Issues. London: Sage. 


\section{O Paradigma Junguiano no Contexto da Metodologia Qualitativa de Pesquisa}

Ellenberger, H. (1970). The discovery of unconscious: the history and evolution of dynamic psychiatry. USA: Basic Books, Harper Collins.

Guba, E. G. (1990). The paradigm dialog. Newbury Park, CA: Sage.

Hauke, C. (2000). Jung and postmodern: the interpretation of realities. London: Routledge Taylor \& Francis Group.

Jacobi, J. (1986). Complexo arquétipo símbolo na psicologia de C. G. Jung. São Paulo: Cultrix. (Trabalho original publicado em 1957)

Japiassu, H., \& Marcondes, D. (2001). Dicionário básico de filosofia. Rio de Janeiro: Jorge Zahar.

Jung, C. G. (1980). Psicologia do inconsciente. In Obras completas de C. G. Jung (Vol. 7/1). Rio de Janeiro: Vozes. (Trabalho original publicado em 1912)

Jung, C. G. (1981). Fundamentos de psicologia analítica. In Obras completas de C. G. Jung (Vol. 18). Rio de Janeiro: Vozes. (Trabalho original publicado em 1935)

Jung, C. G. (1981). Memórias sonhos reflexões. Rio de Janeiro: Nova Fronteira. (Trabalho original publicado em 1961)

Jung, C. G. (1983). The zofingia lectures. In The collected works of C. G. Jung (Suplementary, Vol. A). London: Routledge \& Kegan Paul.

Jung, C. G. (1985). Natureza da psique. In Obras completas de C. G. Jung (Vol. 8/1). Rio de Janeiro: Vozes. (Trabalho original publicado em 1928)

Jung, C. G. (1987). A prática da psicoterapia. In Obras completas de C. G. Jung (Vol. 16). Rio de Janeiro: Vozes. (Trabalho original publicado em 1929)

Jung, C. G. (1990). Freud e a psicanálise. In Obras completas de C. G. Jung (Vol. 4). Rio de Janeiro: Vozes. (Trabalho original publicado em 1929)

Jung, C. G. (1991). Letters II (Gerhard Adler, selected and edited). London: Routledge \& Kegan Paul.

Jung, C. G. (1991). Tipos psicológicos. In Obras completas de C. G. Jung (Vol. 6). Rio de Janeiro: Vozes. (Trabalho original publicado em 1921)

Jung, C. G. (2002). Os arquétipos do inconsciente coletivo. In Obras completas de C .G. Jung (Vol. 9/1). Rio de Janeiro: Vozes. (Trabalho original publicado em 1934)

Kuhn, T. S. (2001). A estrutura das revoluções científicas. São Paulo: Perspectiva. (Trabalho original publicado em 1970)

Lincoln, Y. S., \& Guba, E. G. (1985). Naturalistic inquiry. Newbury Park, CA: Sage.

Mazzotti, A. J. A., \& Gewandsznajder, F. (1998). O método nas ciências naturais e sociais: pesquisa quantitativa e qualitativa. São Paulo: Pioneira. 


\section{Eloisa M. D. Penna}

Nagy, M. (1991). Philosophical issues in the psychology of C. G. Jung. New York: State University of New York Press.

Neumann, E. (1989). The origins and history of consciousness. London: H. Karnac Books. (Trabalho original publicado em 1949).

Penna, E. M. D. (2003). Um estudo sobre o método de investigação da psique na obra de C. G. Jung. Dissertação de mestrado, Programa de Pós-Graduação em Psicologia Clínica, Pontifícia Universidade Católica de São Paulo, São Paulo.

Prigogine, I. (1996). O fim das certezas. São Paulo: Editora da UNESP.

Progoff, I. (1985). Jung's psychology and its social meaning. New York: Dialogue House Library.

Santos, B. S. (2000). Introdução a uma ciência pós-moderna. Rio de Janeiro: Graal.

Schinitman, D. F. (1996). Novos paradigmas, cultura e subjetividade. Porto Alegre: Artes Médicas.

Tarnas, R. (2001). A epopéia do pensamento ocidental. Rio de Janeiro: Bertrand Brasil.

Von Franz, M. L. (1975/1992). C. G. Jung: seu mito em nossa época. São Paulo: Cultrix.

Wehr, G. (1988). Jung - a biography. Boston: Shambhala.

Recebido: 8.12.2004

Revisto em: 3.06 .2005

Aceito em: 20.08.2005 